\title{
HUBUNGAN SOSIODEMOGRAFI DENGAN KEJADIAN FILARIASIS DI KABUPATEN PEKALONGAN
}

\author{
Nola Riftiana dan Soeyoko \\ Fakultas Kesehatan Masyarakat, Universitas Ahmad Dahlan, Yogyakarta
}

\begin{abstract}
Background: Glaucoma is characterized by significantly increase in eye pressure that can lead to order eye diseases including part or total blindness. Glaukoma is still the main eye health problem in Indonesia and Yogyakarta Special Teritory. Glaukoma causes permanen blindness. Based on data from medical records of glaucoma patients who seek treatment at hospital outpatient Eye Dr. Yap Yogyakarta in 2009 amounted to 1302 souls, while in the January to May 2010 amounted to 510 souls. This study aims to determine what factors are associated with the incidence of glaucoma in eye hospital Dr. Yap Yogyakarta.

Methods: This was observational analytic study using case control design (case control) with a ratio of 1:2. Technique of sampling using the Non-Random Sampling, with purposive sampling approach, with a total sample of 105 respondents consisting of 35 cases and 70 controls, data collected by interview with questionnaire guidelines.

Results: test results showed that three variables are not statistically significant and the two variables are statistically significant history of diabetes mellitus (OR $=0.624, \mathrm{p}=0.442, \mathrm{Cl} 95 \%=0.185$ to 2.097 ), history of hypertension ( $\mathrm{OR}=6.401, \mathrm{p}-0,000,95 \% \mathrm{Cl}=2.441$ to 16.784 ), eye trauma (OR $=$ $1.130, p=0.839, \mathrm{Cl} 95 \%=0.348$ to 3.666$)$, complication of eye surgery $(\mathrm{OR}=3.463, \mathrm{p}=0.004,95 \%$ $\mathrm{Cl}-1.444$ to 8.306 ), and the use of corticosteroid drugs (OR-1, 130, $\mathrm{p}=0.839, \mathrm{Cl} 95 \%=0.348$ to 3.666). Results of multivariat test surgery showed that the most dominant variables on the incidence of glaucoma in eye hospital Dr. Yap Yogyakarta is a history of hypertension with Sig $=0.001 \mathrm{Exp}[3=$ 5.675 (95\% Cl:2.105 to 15.301$)$.

Conclusion: There was two variables that is statistically significant, history of hypertension and complications of eye surgery. The most dominant variable with the incidence of glaucoma was a history of hypertension.
\end{abstract}

Keywords: Glaucoma, Complications, Corticosteroids.

\section{PENDAHULUAN}

Filariasis di Indonesia tersebar luas di seluruh propinsi. Program eliminasi filariasis didasarkan atas dasar kesepakatan global WHO yaitu "The Global Goal of Elimination of Lymphatic Filariasis as a Public Health Problem by The Year 2020", yang merupakan realisasi dari resolusi World Health Assembly (WHA) pada tahun $1997^{1}$. Pada tahun 2004, filariasis telah menginfeksi 120 juta penduduk di 83 negara seluruh dunia dan 1/5 penduduk dunia atau 1,1 milyar penduduk di 83 negara berisiko terinfeksi filariasis, terutama di daerah tropis dan subtropis. Penyakit ini tidak mengakibatkan kematian, tetapi dapat mengakibatkan kecacatan seumur hidup, stigma sosial, serta hambatan psikososial sehingga menurunkan produktivitas kerja penderita, keluarga, dan masyarakat yang menimbulkan kerugian ekonomi yang besar².

Kabupaten Pekalongan merupakan salah satu daerah endemis dengan jumlah kasus filariasis meningkat dari tahun ke tahun dengan angka microfilaria rate $1 \%$ atau lebih ${ }^{3}$. penderita filariasis di Kabupaten Pekalongan pada tahun 2007 sebanyak 50 penderita yang tersebar di beberapa kecamatan, dan pada tahun 2009 terdapat 43 kasus filariasis ${ }^{4}$. Berdasarkan latar belakang tersebut mendorong peneliti untuk mengetahui hubungan sosiodemografi dengan kejadian filariasis di Kabupaten Pekalongan. Penelitian ini bertujuan untuk mengetahui hubungan antara umur, jenis kelamin, pekerjaan, dan perilaku dengan kejadian filariasis di Kabupaten Pekalongan. 


\section{METODE PENELITIAN}

Penelitian ini merupakan jenis penelitian observasional analitik dengan menggunakan rancangan studi case control (kasus kontrol) dengan perbandingan 1:1. Populasi dalam penelitian ini adalah seluruh masyarakat Kabupaten Pekalongan.

Sampel dalam penelitian ini adalah seluruh masyarakat yang berada di wilayah Kabupaten Pekalongan yang memenuhi kriteria inklusi dan eksklusi.Teknik pengambilan sampel dengan menggunakan teknik totality sampling. Ditemukan kasus sebanyak 68 orang yang terdiri dari 34 kasus dan 34 kontrol data diambil dengan cara wawancara dengan pedoman kuesioner.

Instrumen yang dipakai dalam penelitian ini adalah kuesioner sebagai pedoman wawancara terstruktur untuk mendapatkan informasi (data primer) yang meliputi identitas responden dan variabel sosiodemografi dengan variabel yang diteliti. Analisis data menggunakan komputerisasi, Analisis data meliputi analisis univariat dan analisis bivariat.

\section{HASIL PENELITIAN DAN PEMBAHASAN}

\section{a. Analisis bivariat (tabulasi silang)}

Hasil analisis bivariat masing-masing variabel bebas terhadap kejadian filariasis di Kabupaten Pekalongan adalah sebagai berikut:

1) Hubungan Antara Umur dengan Kejadian Filariasis

Untuk mengetahui hubungan dan seberapa besar umur responden berisiko dengan kejadian filariasis, dapat dilihat pada tabel 1 berikut.

Tabel 1. Hubungan Umur Responden dengan Kejadian Filariasis

di Kabupaten Pekalongan Tahun 2010

\begin{tabular}{cccccc}
\hline \multirow{2}{*}{ Umur } & \multicolumn{2}{c}{ Filariasis } & & & \\
\cline { 2 - 3 } & Ya & Tidak & Total & $P$ value & OR $(95 \%$ Cl $)$ \\
\hline Ya & $\mathrm{n}$ & $\mathrm{n}$ & & & \\
Tidak & 18 & 14 & 32 & & \\
\hline Total & 16 & 20 & 36 & 0,331 & $1,607(0,616-4,194)$ \\
\hline
\end{tabular}

Besarnya risiko dapat dilihat pada nilai $O R$, dari hasil output diperoleh nilai $O R=1,607$, artinya bahwa orang yang mempunyai umur produktif diperkirakan akan mendapatkan risiko terjadinya filariasis sebesar 1,607 kali lebih besar dari orang yang berumur tidak produktif, tetapi secara statistik tidak bermakna dengan nilai $p=0,331$ pada $\alpha=0,05$.

2) Hubungan Antara Jenis Kelamin dengan Kejadian Filariasis

Untuk mengetahui hubungan dan seberapa besar jenis kelamin dengan kejadian filariasis dapat dilihat pada tabel 2 berikut. 
Tabel 2. Hubungan Jenis Kelamin dengan Kejadian Filariasis

di Kabupaten Pekalongan Tahun 2010

\begin{tabular}{cccccc}
\hline \multirow{2}{*}{$\begin{array}{c}\text { Jenis } \\
\text { Kelamin }\end{array}$} & \multicolumn{2}{c}{ Falariasis } & & & \\
\cline { 2 - 4 } & $\mathrm{n}$ & Tidak & Total & $P$ value & $\begin{array}{c}\text { OR } \\
(95 \% \mathrm{Cl})\end{array}$ \\
\hline $\mathrm{L}$ & 14 & 10 & 24 & & \\
$\mathrm{P}$ & 20 & 24 & 44 & 0,310 & $1,680 \quad(0,615-4,591)$ \\
\hline Total & 34 & 34 & 68 & &
\end{tabular}

Besarnya risiko dapat dilihat pada nilai $O R$, dari hasil output diperoleh nilai $O R=1,680$, artinya bahwa orang yang berjenis kelamin laki-laki diperkirakan akan mendapatkan risiko terjadinya filariasis sebesar 1,680 kali lebih besar daripada perempuan, tetapi secara statistik tidak bermakna dengan nilai $p=0,310$ pada $\alpha=0,05$.

3) Hubungan Antara Pekerjaan dengan Kejadian Filariasis

Untuk mengetahui hubungan dan seberapa besar pekerjaan dengan kejadian filariasis dapat dilihat pada tabel 3 berikut.

Tabel 3. Hubungan Pekerjaan dengan Kejadian Filariasis di Kabupaten Pekalongan Tahun 2010

\begin{tabular}{cccccc}
\hline & \multicolumn{2}{c}{ Filariasis } & & & \\
\cline { 2 - 4 } Pekerjaan & Ya & Tidak & Total & $P$ value & OR $(95 \% \mathrm{Cl})$ \\
& $\mathrm{n}$ & $\mathrm{n}$ & & & \\
Ya & 19 & 9 & 28 & & $3,519(1,270-9,750)$ \\
Tidak & 15 & 25 & 40 & 0,014 & \\
\hline Total & 34 & 34 & 68 & & \\
\hline
\end{tabular}

Besarnya risiko dapat dilihat pada nilai $O R$, dari hasil output diperoleh nilai $O R=3,519$, artinya bahwa orang yang mempunyai pekerjaan selain petani yang dilakukan pada malam hari di luar rumah/ruangan diperkirakan akan mendapatkan risiko terjadinya filariasis sebesar 3,519 kali lebih besar daripada orang yang bekerja siang hari dan secara statistik bermakna dengan nilai $p=0,014$ pada $\alpha=0,05$.

4) Hubungan Antara Perilaku dengan Kejadian Filariasis

Untuk mengetahui hubungan dan seberapa besar perilaku dengan kejadian filariasis dapat dilihat pada tabel 4 berikut.

Tabel 4. Hubungan Perilaku dengan Kejadian Filariasis di Kabupaten Pekalongan Tahun 2010

\begin{tabular}{|c|c|c|c|c|c|}
\hline \multirow{3}{*}{ Perilaku } & \multicolumn{2}{|c|}{ Filariasis } & \multirow{3}{*}{ Total } & \multirow{3}{*}{$P$ value } & \multirow{3}{*}{ OR $(95 \% \mathrm{Cl})$} \\
\hline & Ya & Tidak & & & \\
\hline & $\mathrm{n}$ & $\mathrm{n}$ & & & \\
\hline Negatif & 18 & 15 & 33 & \multirow{3}{*}{0,467} & \multirow{3}{*}{$1,425(0,548-3,703)$} \\
\hline Positif & 16 & 19 & 35 & & \\
\hline Total & 34 & 34 & 68 & & \\
\hline
\end{tabular}


Besarnya risiko dapat dilihat pada nilai $O R$, dari hasil output diperoleh nilai $O R=1,425$, artinya bahwa orang yang mempunyai perilaku yang kurang baik yang mendukung terjadinya filariasis diperkirakan akan mendapatkan risiko terjadinya filariasis sebesar 1,425 kali lebih besar daripada orang yang mempunyai perilaku baik atau dapat menghindari kebiasaan yang mendukung terjadinya filariasis, tetapi secara statistik tidak bermakna dengan nilai $p=0,467$ pada $\alpha=0,05$.

\section{b. Pembahasan}

Berdasarkan penelitian yang dilakukan di wilayah Kabupaten Pekalongan pada tahun 2010, terhadap 68 responden dengan perbandingan 1 banding 1 antara kasus dan kontrol. Ditemukan hubungan yang bermakna secara biologis pada semua variabel yang diteliti, secara statistik tidak ada hubungan yang bermakna antara umur, jenis kelamin dan perilaku terhadap filariasis, dan terdapat hubungan yang bermakna antara pekerjaan dengan kejadian filariasis.

1) Hubungan Antara Umur dengan Kejadian Filariasis

Dari hasil penelitian yang dilakukan di wilayah Kabupaten Pekalongan diperoleh hasil $O R=1,607$ dan $p$ value $=0,331$ pada $\alpha=0,05$. Hal ini berarti secara kemaknaan biologis, orang yang mempunyai umur produktif diperkirakan akan mendapatkan risiko terjadinya filariasis sebesar 1,607 kali lebih besar daripada orang yang berumur tidak produktif, tetapi secara statistik tidak bermakna. Penelitian ini sejalan dengan penelitian ${ }^{5}$, didapatkan hasil $p=$ 0,387 yang menunjukkan tidak ada hubungan yang bermakna antara umur dengan kejadian filariasis. Terjadinya filariasis tergantung dari tingkat endemisitas suatu daerah dan dapat berlangsung lama, satu tahun atau mungkin bertahun-tahun. Namun, berbeda dengan hasil penelitian ${ }^{6}$ diperoleh hasil $R R$ sebesar 6,83 yang menyebutkan variabel umur berhubungan dengan kejadian filariasis. Hal ini terjadi karena tingginya aktivitas penduduk dewasa dibandingkan penduduk dengan usia yang lebih muda.

Tidak berhubungannya variabel umur dengan kejadian filariasis mungkin disebabkan oleh adanya faktor lain selain umur, yang juga merupakan faktor intern (bawaan) yang melekat pada individu. Walaupun umur individu yang satu dengan yang lain sama, tetapi bila berbeda kecerdasan, persepsi, emosi, dan motivasi maka akan memberikan perilaku yang berbeda pula ${ }^{7}$. Demikian juga walaupun individu tua memiliki pengalaman yang lebih banyak daripada yang muda, tidak dapat memberikan jaminan bahwa mereka memiliki perilaku yang baik, karena pada dasarnya setiap individu akan memberikan respon yang berbeda walaupun objeknya sama. Hal ini disebabkan oleh sifat khas dari individu itu sendiri. Oleh sebab itu perbedaan umur tidak menyebabkan perbedaan tindakan dalam pencegahan filariasis.

2) Hubungan Antara Jenis Kelamin dengan Kejadian Filariasis

Dari hasil penelitian yang dilakukan di wilayah Kabupaten Pekalongan diperoleh hasil $O R=1,680$ dan $p$ value $=0,310$ pada $\alpha=0,05$. Hal ini berarti secara kemaknaan biologis, laki-laki diperkirakan akan meningkatkan risiko terjadinya filariasis sebesar 1,607 kali lebih besar daripada laki-laki, tetapi secara statistik tidak bermakna. Penelitian ini sejalan dengan penelitian $^{5,8}$. penelitian ${ }^{5}$ didapatkan hasil $P=0,344$ yang menunjukkan bahwa tidak ada hubungan yang bermakna antara jenis kelamin dengan kejadian filariasis. Sedangkan penelitian ${ }^{8}$ didapatkan hasil $O R=2,6$ dengan nilai $X^{2}=$ 2,$17 ; p>0,05$. 
Tidak berhubungannya variabel jenis kelamin dengan kejadian filariasis di Kabupaten Pekalongan dapat terjadi karena baik laki-laki maupun perempuan mempunyai kesempatan yang sama untuk terinfeksi filaria $W$. bancrofti. Laki-laki yang mencari nafkah dengan berdagang atau buruh di luar rumah pada malam hari untuk mencukupi kebutuhan sehari-hari, sedangkan perempuan kebanyakan menjadi buruh batik di luar rumah pada malam hari untuk mendapatkan penghasilan tambahan. Hal ini mengakibatkan variabel jenis kelamin tidak berhubungan dengan kejadian filariasis sesuai dengan penelitian ${ }^{9}$ bahwa filariasis pada wanita lebih banyak ditemukan dibandingkan dengan laki-laki dan dapat disimpulkan terjadinya penularan filariasis bersifat lokal spesifik sesuai dengan keadaan dan situasi setempat.

3) Hubungan Antara pekerjaan dengan Kejadian Filariasis

Hasil penelitian yang didapatkan diperoleh nilai $O R=3,519, p=0,014$ pada $\alpha=0,05$. Secara kemaknaan biologis, hal ini berarti pekerjan selain petani yang dilakukan pada malam hari akan meningkatkan risiko terjadinya filariasis sebasar 3,519 kali dibandingkan dengan orang yang bekerja pada siang hari dan secara statistik bermakna. Hal ini sejalan dengan penelitian ${ }^{6}$ dengan nilai $R R=8,40$ dan $C l(1,13-62,53)$ yang berarti secara biologis maupun statistik ada hubungan antara pekerjaan dengan kejadian filariasis. Namun, berbeda dengan penelitian ${ }^{5,8}$, penelitian ${ }^{5}$ diperoleh hasil $p=0,995$, sedangkan penelitian ${ }^{8}$ didapatkan hasil $\left(X^{2}=1,40 ; p>0,05\right)$ yang berarti secara statistik tidak ada hubungan yang bermakna antara jenis pekerjaan dengan kejadian filariasis.

Masyarakat di wilayah Kabupaten Pekalongan sebagian besar mempunyai mata pencaharian berdagang ataupun buruh/tukang. Hal ini dapat dilihat dari 68 responden yang diwawancarai terdapat $47,0 \%$ warga yang memiliki mata pencaharian buruh/tukang, seperti buruh batik yang memungkinkan mereka keluar rumah pada malam hari ke rumah tetangga untuk menyelesaikan pekerjaannya. Mereka kadang tidak sadar bahwa tubuh mereka dihisap nyamuk saat membatik. Terdapat 30,9\% warga yang memilki pekerjaan sebagai pedagang/wiraswasta, dan kegiatan tersebut dilakukan pada malam hari sehingga memungkinkan mereka terpapar oleh gigitan nyamuk.

4) Hubungan Antara Perilaku dengan Kejadian Filariasis

Munculnya perilaku banyak dipengaruhi oleh kebiasaan atau keyakinan/ kepercayaan suatu masyarakat, baik secara langsung atau tidak. Kebiasaan dan kepercayaan merupakan hal yang saling berkaitan dalam kehidupan sehari-hari. Perilaku yang positif seperti halnya kebiasaan menggunakan kelambu, pemakaian obat nyamuk/reffelent sangat mendukung upaya pencegahan dan pemberantasan filariasis. Demikian juga kepercayaan masyarakat terhadap suatu penyakit dapat berpengaruh terhadap perilaku. Misalnya, sebagai penyakit guna-guna, maka kepercayaan itu dapat berpengaruh terhadap upaya pencarian pengobatan.

Hasil penelitian yang didapatkan diperoleh nilai $O R=1,425, p=0,467$ pada $\alpha=0,05$. Hal ini berarti orang yang berperilaku kurang baik yang mendukung terjadinya filariasis akan meningkatkan risiko terjadinya filariasis sebesar 1,425 kali lebih besar daripada orang yang mempunyai perilaku baik atau dapat menghindari kebiasaan yang mendukung terjadinya filariasis, tetapi secara statistik tidak bermakna. Hal ini sejalan dengan penelitian yang dilakukan oleh Munir (2007) yang menyebutkan tidak adanya hubungan yang bermakna antara perilaku dengan kejadian filariasis. Tidak berhungannya variabel 
perilaku dalam penelitian filariasis di Kabupaten Pekalongan disebabkan karena kasus dan kontrol memiliki kesempatan yang sama untuk terkena infeksi filaria. Antara kasus dan kontrol sama-sama memiliki perilaku yang kurang baik/mendukung terjadinya filariasis.

\section{SIMPULAN DAN SARAN}

\section{a. Simpulan}

1) Tidak ada hubungan yang bermakna secara statistik antara umur dengan kejadian filariasis di Kabupaten Pekalongan $(P=0,331$; $O R=1,607 ; 95 \% \mathrm{Cl} 0,616$ 4,194).

2) Tidak ada hubungan yang bermakna secara statistik antara jenis kelamin dengan kejadian filariasis di Kabupaten Pekalongan ( $\mathrm{P}=0,310 ; O R=1,680 ; 95 \%$ Cl 0,615-4,591).

3) Ada hubungan yang bermakna secara statistik antara pekerjaan dengan kejadian filariasis di Kabupaten Pekalongan $(\mathrm{P}=0,014$; $O R=3,519 ; 95 \% \mathrm{Cl} 1,270$ 9,750).

4) Tidak ada hubungan yang bermakna secara statistik antara perilaku dengan kejadian filariasis di Kabupaten Pekalongan $(P=0,467$; $O R=1,425 ; 95 \% \mathrm{Cl} 0,548$ $3,703)$.

\section{b. Saran}

1) Bagi Dinas Kesehatan Kabupaten Pekalongan

Dinas kesehatan Kabupaten Pekalongan sebagai penentu kebijakan mengenai kesehatan di Kabupaten Pekalongan agar lebih meningkatkan Komunikasi Informasi dan Edukasi (KIE) yang optimal dan terpadu tehadap tindakan pencegahan dan pemberantasan penyakit, terutama penyakit filariasis.

2) Bagi Puskesmas Kabupaten Pekalongan

a) Melaksanakan penyuluhan kesehatan bagi warga masyarakat, khususnya tentang penyakit filariasis.

b) Mengoptimalkan segenap tenaga agar kasus klinis filariasis dapat terdeteksi secara dini.

c) Membentuk pengawasan minum obat ketika pengobatan massal dilaksanakan agar obat yang diberikan diminum oleh masyarakat.

d) Membentuk tenaga eliminasi filariasis lintas sektor.

3). Bagi masyarakat Kabupaten Pekalongan
a) Bila memungkinkan tidak bekerja pada malam hari.
b) Memakai pakaian yang menutupi seluruh bagian tubuh agar terhindar dari gigitan nyamuk ketika keluar rumah.
c) Memakai reffelent ketika keluar rumah.
d) Memakai obat nyamuk/reffelent/kelambu pada saat tidur.
e) Memperhatikan kebersihan lingkungan tempat tinggal agar tidak menjadi tempat bersarangnya nyamuk.
f) Memakan obat yang diberikan ketika pengobatan massal.

4) Bagi peneliti lain 
Penelitian lain agar dilanjutkan, tentang bionomic (tata hidup) vektor, yang mencakup tempat berkembangbiak, perilaku menggigit (mencari darah) dan tempat istirahat nyamuk di Kabupaten Pekalongan.

\section{KEPUSTAKAAN}

1. Departemen Kesehatan RI, Pengendalian Penyakit Filariasis, Ditjen PP \&PL: http:// www.pppl.depkes.go.id/images_data/PROFIL\%20\%20PP\&PL\%202008.pdf diambil pada tanggal 4 Juni 2010, Yogyakarta. 2009,

2. Departemen Kesehatan Republik Indonesia, Epidemiologi Filariasis, Jakarta. 2006,

3. Febriyanto, B., Astri Maharani I.P. dan Widiarti, "Faktor Risiko Filariasis di Desa Samborejo, Kecamatan Tirto, Kabupaten Pekalongan Jawa Tengah", Buletin Penelitian Kesehatan, Vol. 36, No. 2, 48 - 58, Yogyakarta. 2008,

4. Mulyono, R. A., Hadisaputro, S. dan Wartomo, H., "Faktor Risiko Lingkungan dan Perilaku yang Berpengaruh terhadap Kejadian Filariasis (Studi Kasus di Wilayah Kerja Kabupaten Pekalongan)", Jurnal Epidemiologi, Yogyakarta. (2008),

5. Munir, M., Filariasis dan Faktor-Faktor yang Berkaitan dengan Kejadian Filariasis di Desa Bitahan Kecamatan Lokpaikat Kabupaten Tapin Propinsi Kalimantan Selatan, Tesis, Program Pascasarjana UGM, Yogyakarta. 2007,

6. Rahayu, N., Faktor yang Berhubungan dengan Penularan Filariasis di Puskesmas Lasung Kecamatan Kusan Hulu Kabupaten Tanah Bumbu Propinsi Kalimantan Selatan, Tesis, UGM, Yogyakarta. 2008,

7. Notoatmodjo, S., Promosi Kesehatan dan IImu Perilaku, Rineka Cipta, Jakarta. 2007,

8. Sumarni, S. dan Soeyoko, "Filariasis Malayi di Wilayah Puskesmas Cempaka Mulia, Sampit Kalimantan Tengah (Beberapa Faktor yang Mempengaruhi Penularannya)", Berita Kedokteran Masyarakat XIV (3): 143-148, Yogyakarta. 1998,

9. Supali, T., Kurniawan, A., Oemijati, S., Parasitologi Kedokteran, Edisi IV, Balai Penerbit FKUI, Jakarta. 2008, 
